\title{
IGNACIO SÁNCHEZ MEJÍAS, UN PERIODISTA DE PERSONALIDAD INQUIETA
}

\author{
IGNACIO SÁNCHEZ MEJÍAS, \\ AN ENTERPRISING JOURNALIST
}

AUTOR

Dr. Juan Carlos Gil González

Universidad de Sevilla (España)

jcgil@us.es

\section{RESUMEN}

El artículo se centra en el estudio de las crónicas taurinas del matador de toros sevillano I gnacio Sánchez Mejías, único caso en la historia del toreo que enjuició la labor de sus compañeros y la suya propia. Además, profundiza por primera vez en la polémica sobre la censura que se desarrolló en el periódico madrileño El Heraldo de Madrid. Lo más destacado de la polémica son los argumentos a favor de las corridas de toros y el apoyo que para el tema de la expresión libre del pensamiento en letra impresa recibió de Miguel de Unamuno.

\section{PALABRAS CLAVE}

Crónica taurina - Historia del periodismo - Censura. 


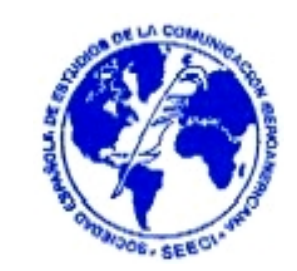

\section{ABSTRACT}

This article studies the bullfighting chronicles of Ignacio Sanchez Mejías, the only case in the History of Bullfight who judged his fellows and himself. In addition, our work deepens in the censorship's polemic in the newspaper El Heraldo de Madrid. The most interesting of the polemic they are the arguments that defend the bullfights and the support that Sanchez Mejías received of Miguel de Unamuno.

\section{KEY WORDS}

Bullfighting chronicle - History of the journalism - Censorship.

\section{ÍNDICE}

1. Radiografía de la personalidad de Ignacio Sánchez Mejías.

2. I gnacio Sánchez Mejías, cronista taurino.

3. Los artículos de la polémica en El Heraldo de Madrid.

4. Conclusión.

5. Bibliografía

\section{Radiografía de la personalidad de Ignacio Sánchez Mejías}

Sánchez Mejías es un hijo del momento atormentado de su tiempo. Nació en Sevilla en 1890, justo un año antes de que se promulgase por primera vez el sufragio universal en España y en la misma década en que nuestro país perdió el último reducto colonial que le quedaba del Imperio que se formó en el siglo XVI. Por tanto, 


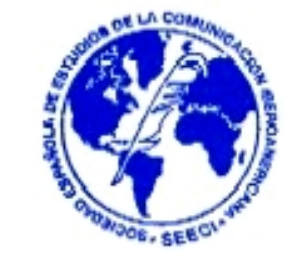

su infancia y su niñez van a estar marcada por los acontecimientos finiseculares que supusieron un grave padecimiento al ser de España.

No puede haber confianza social en quien se presta a ejercer una tarea sin haberse previamente formado para ella. Y aunque en 1929, I gnacio Sánchez Mejías ya era un personaje público que ejercía con solvencia y brillo sus variados talentos, optó por poner fin a lo que había iniciado muchos años antes para ganarse merecidamente el apelativo de intelectual. Impulsado por sus amigos poetas, el matador de toros decidió examinarse de las seis asignaturas que tenía pendientes para acabar sus estudios de bachillerato en el instituto onubense de La Rábida. Desde entonces su inquietud y sed de conocimiento fueron casi insaciables y su entusiasmo por la cultura popular, por la literatura, por la filosofía, por el teatro se convirtió en una constante desbordante.

Hombre de cortesía antigua, dueño de una elegancia intelectual acorde a su porte físico de patricio cosmopolita, trató con un entusiasmo generoso a los poetas vanguardistas, hecho nada habitual en los toreros de su época. Pero además no se conformó con ser un simple mecenas, sino que, como cualquier caballero andante de las letras, buscó su propio espacio dentro del mundo que le rodeaba. Se interesó desenfrenadamente por la acción, el héroe mítico, la creación de mundos ficticios y su enfrentamiento con el mudo real. Su obra de teatro Sinrazón y los artículos sobre la censura publicados en El Heraldo de Madrid pueden entenderse como un milimétrico reflejo de una personalidad que pretende ser un grito de rechazo a la mediocridad.

En esos retazos se observa con meridiana claridad su tozuda defensa de la libertad y la fecundidad aplastante de sus reflexiones sociopolíticas. Y algo más, suficientemente inusual como para ser recordado tras el paso de su historia: la decencia de su postura inalterable ante las dictaduras de la pluma periodística al servicio de intereses espurios era una actitud vital. Que se sepa, Ignacio Sánchez 


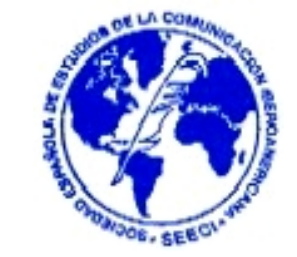

Mejías jamás coqueteó con los filibusteros del periodismo para ganarse su favor con fraude de ley. Al contrario, pudo exhibir sin complejos una decencia poco usual en su gremio, muy dado a dejar en manos de terceros sin escrúpulos la fontanería de los bajos fondos. Su aventura de intentar combatir de frente los hechos injustos no mordió su prestigió taurino aunque sí le generó un sinfín de enemistades.

La rectitud moral de su pensamiento puede comprobarse en la actitud que mantuvo en 1925 cuando, nombrado presidente de la Asociación de Matadores de Toros, se enfrentó al mundo empresarial con uñas y dientes, lo que le valió quedarse fuera de los carteles de la feria de abril de Sevilla por defender sus honorarios. Sin embargo, así se expresó en la cena-homenaje que le rindieron las gentes del toro:

"Yo he ido al pleito taurino porque lo consideraba una cosa esencialísima y necesaria para la fiesta de toros (...). El traje de torero no es ni podrá ser un ningún caso confundido con la librea del lacayo. La sangre que mana de nuestras heridas, derramada en las plazas de toros, sirve de motivo para el enriquecimiento de las empresas (...). Yo, que debo el haber subido a la presidencia de la Asociación al esfuerzo de los modestos toreros que me honraron con su voto, estoy obligado a defenderlos. Porque a mí no me han votado los de arriba, sino los de abajo" (Amorós, 1999, p. 103).

Torero dominador y a veces excepcional, dotado de un temperamento refinado e inquieto, fue un ejemplo de rigor y seriedad en todos los ámbitos por los que transitó. Algunos pueden fácilmente obtener grandes éxitos mediáticos por sus logros efectistas; sin embargo, cuando aparece un torero auténtico en la plaza pública se acaba el circo. Allí nace una cosa muy distinta, algo de naturaleza casi indescriptible, remoto, ancestral y a la vez fugaz. Quizá se trata simplemente de la cita del hombre con lo sagrado. La peculiaridad de Ignacio Sánchez Mejías reside en que no sólo provocaba esa impresión en el ruedo sino en casi todas las empresas 


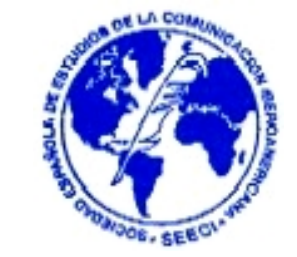

que iniciaba, desde la presidencia de la Cruz Roja hasta la lectura del primer capítulo de su novela "La amargura del triunfo" en el teatro de Valladolid.

La realidad sólo contiene interés cuando está modificada y manipulada por los artistas. Entre todos los sonidos de la naturaleza, ninguno de ellos es tan sublime como una sinfonía de Mozart; entre la variedad de rostros humanos ninguno resultará tan impresionante como el de la Gioconda; entre las oscuras pasiones de los individuos, ninguna será tan estremecedora como la de Macbeth; entre todas las representaciones de la vida y la muerte ninguna será tan dramática y conmovedora como las faenas de Ignacio Sánchez Mejías, que sentía en el interior de su ser un irrefrenable y misterioso impulso creativo. Estos artistas que dieron vida a estas obras sentían la irresistible necesidad de conmover al prójimo mediante la transformación de unas materias muy sencillas: vocabulario en Shakespeare, pigmentos en Leonardo; las siete notas básicas en Mozart, pero el caso de Ignacio Sánchez Mejías representa la máxima pureza del arte, pues se jugó la vida hasta perderla por el placer de generar en los demás sensaciones indescriptibles. Un acto que viene a significar la hombría de la antigüedad mitológica.

El matador de toros sevillano vivió el arte como un designio interior antes que nada e interpretó el toreo y la escritura con total sinceridad muriendo en cada texto y en cada paseíllo con pasmosa naturalidad. El arte en su más extensa dimensión fue una forma de sentirse libre, en paz consigo mismo. Fue una forma de ver y entender el mundo, con lo cual, o disfrutaba con su tauromaquia o padecía el dolor más desgarrado en el alma.

Brillante, culto, educado, versátil, seductor, mediático, polémico... son rasgos definitorios de la personalidad de Ignacio Sánchez Mejías, que gracias a su carácter entusiasta e impulsivo supo emplearlos para convertirse en el paradigma de torero histórico, no sólo por lo que hizo en el ruedo sino por la estela que dejó en otros senderos artísticos. Como la ética torera es una moral del individuo excepcional que 


\section{REVISTA DE LA SEECI.}

Gil González, Juan carlos (2010): Ignacio Sánchez Mejías, un periodista de personalidad inquieta. No 21. Marzo. Año XIV. Páginas: 44-70

ISSN: 1576-3420 DOI: http://dx.doi.org/10.15198/seeci.2010.21.44-70

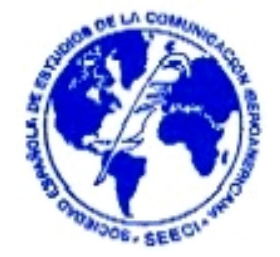

busca la excelencia suprema ocurra lo que ocurra, I gnacio Sánchez Mejías se adentró de lleno en la batalla periodística con pluma de hierro. Utilizó su fina inteligencia para denunciar los sobornos, las compañas en su contra y para defender las causas que él siempre consideró justas. En el ámbito periodístico jamás renunció a la batalla y mantuvo una ejemplar rectitud, es decir, una actitud inmutablemente vertical que ni la comodidad ni la necesidad pudieron quebrantar.

En este artículo tratamos de ofrecer algunas respuestas que explican por qué se embarcó en esta fascinante y sorprendente actividad pública que lo mantuvo en un fuego cruzado constante. Hasta donde se sabe, el quehacer periodístico del matador de toros sevillano puede reputarse como histórico, pues no ha habido ningún caso en la poliédrica historia de la Tauromaquia en que un torero haya enjuiciado la labor de sus compañeros de cartel y haya firmado su propia autocrítica, además, justo en la página siguiente en la que aparecía publicada la crónica oficial del periodista del diario La Unión.

Por otro lado, estos textos periodísticos suponen el primer ensayo literario y la primera toma de contacto con una audiencia con la que llegó a mantener una cercanía simbólica y no pocas complicidades. Posiblemente el hallazgo más sobresaliente de este artículo radique en el estudio de los textos sobre la censura periodística y la defensa ética de la Tauromaquia que protagonizó Ignacio Sánchez Mejías en el Heraldo de Madrid allá por el año 1929. Fueron seis columnas cuya existencia se desconocía hasta que se publicó el libro titulado "Sobre Tauromaquia. Obra periodística, conferencias y entrevistas" (Gil González, J.C., 2010, p. 65-95).

El primero fue una respuesta al ataque indirecto pero incisivo a las corridas de toros de José María Salaverría publicado en $A B C$ ( $A B C, 23$ de mayo de 1929, p. 7). El argumentario empleado por el torero tuvo tal cariz e hizo tales comparaciones con el pueblo alemán que la indecorosa censura se vio obligada a recortar el texto del espada. Se exaltaron tanto los ánimos del protagonista que decidió abandonar, por 


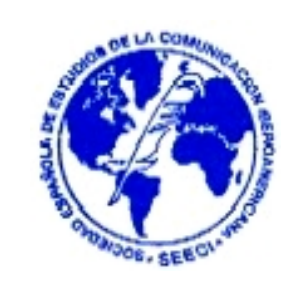

un momento, la defensa de las corridas y reflexionar aguda e irónicamente sobre esa dama de manos rojas. Fue noticia que un patriota como Ignacio Sánchez Mejías cayese en las zarpas de la censura, hasta tal punto, que el mismísimo Miguel de Unamuno le escribió una carta a favor de su apuesta decida contra libertad de expresión. Dicha carta se encuentra manuscrita y perfectamente conservada en el archivo familiar del torero, actualmente custodiado por sus herederos, y que en este artículo reproducimos.

Gracias estos artículos periodísticos podemos hacernos una idea de la capacidad argumentativa de uno de los principales protagonistas de la vida pública de la década de los años veinte del siglo pasado, que fue dichoso porque su destino se completó como un arco cerrado, trágicamente perfecto. Ignacio Sánchez Mejías se consagró como héroe popular y universal en Manzanares, pues su tragedia personal y el poema de Federico García Lorca lo convirtieron en un símbolo de la memoria colectiva.

\section{Ignacio Sánchez Mejías, cronista taurino}

La crónica periodística es un texto complejo, escurridizo y multiforme que se caracteriza porque participa de casi todas las singularidades de los otros géneros de la comunicación. Posee rasgos de la noticia cuando informa de lo sucedido en un lugar determinado; contiene elementos del análisis cuando enjuicia los quehaceres de los protagonistas de cualquier evento; incorpora los métodos interpretativos del reportaje para explicar al lector el sentido último de los hechos; y explica las técnicas de los artistas en su relación con el contexto cultural y social que es lo propio de las críticas de arte. La parte es el todo y cada crónica es diferente, irreductible e irrepetible, precisamente porque arrastra consigo una gran parte de la personalidad y experiencia de la persona que la firma. 


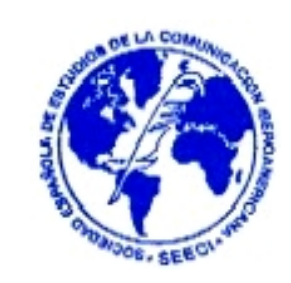

Es plural, híbrida y proclive a transformarse según nos encontremos ante un acontecimiento u otro puesto que su finalidad, en tanto que género interpretativo, es explicar la historia psicológicamente, pero también ofrecer la psicología de la historia de cualquier hecho que pueda generar opinión. La crónica nos propone la interpretación informativa junto a la opinión como información. En su esencia, forma y substancia van entrelazadas porque su contenido relaciona un hecho con varias ideas o viceversa. Aparece, por tanto, como un magnífico lugar de encuentro entre el ars bene dicendi y el enjuiciamiento de los hechos narrados.

Además de su carácter múltiple, el otro rasgo definitorio de la crónica es su firma. Desde sus relaciones con la Historia, pasando por las variadas influencias recibidas de la Literatura, hasta su adopción por el Periodismo moderno, el cronista siempre fue una persona que firmó sus escritos porque su prestigio y responsabilidad agregaban a la interpretación un valor añadido. Sin la presencia lingüística del intérprete, a través de los deícticos o de los verbos en presente o de la primera persona del singular, la crónica se asemejaría a una simple noticia simple. En este género la autoría se cotiza como en ningún otro texto periodístico, puesto que como perfectamente ha sostenido Foucalut "el autor hay que entenderlo como principio de agrupación del discurso, como unidad y origen de sus significaciones, como foco de su coherencia" (Foucautl, M., 1999).

El cronista es un observador excepcional que otea los hechos desde un lugar privilegiado y dibuja los hechos partiendo de los antecedentes e incorporando su experiencia. Emplea, adapta y selecciona del contexto. Transfigura todos esos materiales y los conjuga con su sapiencia para ofrecer una narración compuesta de diálogos, descripciones, comparaciones, metáforas... es decir, un texto único. La operación innovadora y sui generis consiste en posibilitar que los elementos empleados abandonen el mundo de la naturaleza para ingresar en el de las significaciones. La retórica, la estilística, la sociología, la historia y hasta la psicología son disciplinas que debe dominar un buen cronista para cumplir con su cometido. 


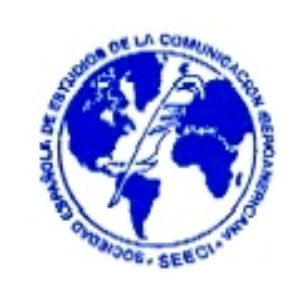

La crónica, desde nuestra perspectiva, debe entenderse como una interpretación informativa sobre un acontecimiento determinado, narrado por un cronista-testigo, que además de ser un especialista en la materia tratada, debe ofrecer un juicio argumentado y valorativo sobre lo presenciado, con un estilo sugestivo y personal que atraiga a los lectores con la finalidad de convertirlos en audiencia. Su estructura narrativa y descriptiva no está predeterminada a priori, es una licencia del firmante que, sin embargo, debe equilibrar la información con el comentario, es decir, su sapiencia con los hechos de referencia, pues nunca debe olvidar el principal objetivo del género: informar.

La crónica, por tanto, es cultura y pensamiento expresado en tipografía impresa. Es la síntesis y mixtura de todos los géneros. Aglutinadora de opiniones, comentarios e interpretaciones, ofrece información original, visiones sesgadas de las cosas y erudición en la exposición de argumentos. Pretende explicar el porqué, el cómo y el para qué de los hechos, buscando desenmarañar el sentido general de un acontecimiento. El cronista, cuando construye una trama, narra un hecho aunando datos y argumentos que corroboren lo afirmado, negado o interpretado en su discurso. Si el cronista adquiere la credibilidad suficiente ante su audiencia consigue que sus relatos sean asumibles intelectualmente por los receptores, es decir, aquéllos se hacen verosímiles sin necesidad de una constatación fehaciente por parte del receptor.

A lo largo de la historia casi todos los cronistas taurinos se han preocupado por alcanzar notables niveles de calidad literaria. Para desempeñarse con soltura dentro de las exigencias de la crónica taurina hay que adornarse de tres grandes saberes. Según señala Pedro Laín Entralgo:

"La práctica responsable de la crítica (crónica) exige la posesión de un saber histórico: el crítico (cronista) debe conocer suficientemente la historia de la actividad cuyas obras comenta. Un saber técnico: el crítico (cronista) debe tener una información suficientemente precisa 


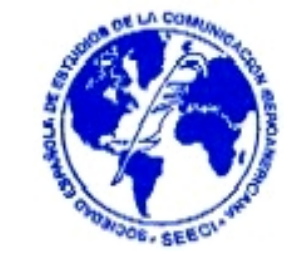

acerca de cómo ha sido ejecutada la obra que va a comentar. Un saber teorético: el crítico (cronista) debe tener alguna idea de lo que en sí misma y en su relación con la vida humana es la actividad o la obra por él criticada. Y a todo ello debe unirse, para que la crítica (crónica) alcance perfección y eficacia, algo sin lo cual nadie debería entrar en el mundo de la letra impresa: el bien escribir, el ejercicio de un estilo correcto, $y$ en la medida de lo posible, atractivo" ${ }^{1}$.

Ignacio Sánchez Mejías saltó de espontáneo al ruedo periodístico en enero de 1925 y a al albero maestrante el 21 de abril del mismo año, en protesta por haberse quedado fuera de los carteles debido al pulso que le enfrentaba a la empresa de Sevilla por los honorarios de los matadores. Decidió arrojarse al ruedo en el segundo toro de Agüero y banderillearlo con él vestido con un traje de chaqueta. La polémica se desgreñó en los medios, sobre todo en El Liberal y en Seda y Oro, donde publicaban sus dos grandes rivales, Antonio Reyes, Don Criterio y Agustín López Macías, Galerín. Al día siguiente el periódico La Unión anunciaba el desembarco del espada en la arena de la crónica taurina: "Sánchez Mejías va a hacer la autocrítica de su labor en las Plazas de toros, a la vez que el juicio respecto de la actuación de sus compañeros de carteles" (Amorós, A., 1998, p. 108).

De todos los textos que publicó I gnacio Sánchez Mejías en La Unión desde el 16 de abril hasta el 25 de julio de 1925, nosotros consideramos crónicas taurinas: "La primera de Jerez" (24 de abril); "El toro embolado de Coimbra" (28 de abril); "Las enemistades de Aliatar" (30 de abril); "En Melilla no se puede chaquetear" (13 de mayo); "Ése es el hijo del amo..." (15 de mayo); "La casa de todos los toreros" (26 de mayo); "La corrida de Santoña" (25 de julio); el resto de textos pertenece a otros géneros periodísticos, aunque muchos biógrafos los hayan catalogado infundamente como crónicas taurinas.

\footnotetext{
${ }^{1}$ Laín Entralgo, P. “Prólogo” en Corrochano, G. Tauromaquia. Madrid, Espasa, 1999. P. 10.
} 


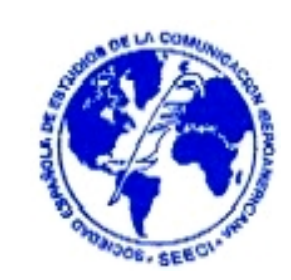

Todas estas crónicas coinciden en el mismo esquema estructural. Comienzan por una pequeña introducción de lo más variada temáticamente; una parte central en la que se conjugan los datos "objetivos" con el comentario del cronista; y finalmente un párrafo de cierre que suele engarzar el final con el tema de la crónica. Como ejercicio estético el titular y el párrafo de cierre conforman la macroestructura de la crónica, según sostiene Van Dijk (Van Dijk, T., 1983, p. 144). El titular será el tema que condicione la lectura del texto, el matiz que esclarecerá el sentido de la narración, la pista que configurará el significado de los implícitos y los dobles sentidos, e incluso, será el señuelo que permitirá aclararnos los sobrentendidos. Además, los titulares de este puñado de crónicas, en líneas generales y como exige el género, suelen estar compuestos de un sintagma nominal nada informativo que hace las funciones de rótulo exclamativo cuya función es atraer la atención del lector, como por ejemplo "El toro embolado de Coimbra".

En esta crónica, por ejemplo, el enigma de ese rótulo se resuelve en el párrafo de cierre que abrocha el hilo argumental, es decir, nos encontramos ante una suerte de conclusión moral sobre lo explicado a lo largo de toda la crónica, como si estuviésemos ante la moraleja de una fábula. Por ello, todos los matices que se han ido ofreciendo a lo largo del texto encuentran su colofón en dicho lugar, espacio en el que el narrador expone su opinión de forma más contundente y resumida. Esta parte final constituye el comentario, la glosa decisiva, el juicio ponderado en el que, Ignacio Sánchez Mejías, en tanto que entidad textual, ofrece los rasgos definitorios de su carácter: "Yo me acordaré durante mucho tiempo del toro embolado de Coimbra, que no me dejó armar una revolución en Lisboa" (Gil González, J.C., 2010, p. 17).

El ejemplo que mejor representa este armazón puede leerse en la crónica titulada "Las enemistades de Aliatar" pues con ese nombre se refiere Ignacio Sánchez Mejías don Julián Salgueiro, empresario de la plaza de toros de Sevilla (recuérdese que 


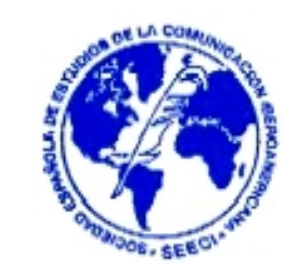

dicho apelativo había sido propuesto por Corrochano para referirse al empresario de Sevilla). Sólo sabiendo ese dato se comprende la frase de cierre de la crónica en el que hace referencia a unos hechos que no están vinculados a lo acontecido en el ruedo, pues se refieren a una corrida celebrada en la Real Maestranza, en la que Ignacio Sánchez Mejías, al no estar incluido en los carteles, no pudo participar. La crónica concluye de esta guisa: "indudablemente, la plaza de la Maestranza tiene buena suerte para las enemistades de Aliatar" (Gil González, J.C., 2010, p. 20). Es decir, engrandece el triunfo de su compañero aunque eso signifique dar la razón, si quiera indirectamente, al empresario y sus adversarios periodísticos, que habían censurado su actitud al quedarse fuera del abono.

Ahora bien, entre la propuesta inicial y la conclusión, nos encontramos con un sabroso muestrario de argumentos. El narrador no trata sólo de explicar qué ha pasado en una tarde de toros sino también cómo y por qué ha ocurrido. Para ello, Ignacio Sánchez Mejías le concede una gran importancia a la presentación y comportamiento de los toros, de ahí que no haya ninguna crónica en la que no se haga referencia a este aspecto. Su función, recordemos, no es sólo describir sino también argumentar partir de su experiencia lo que, en el caso especial de Ignacio Sánchez Mejías, es él mismo el protagonista de los hechos. Reinterpretando los postulados de Van Dijk, los bloques textuales en los que se analizan de forma breve, sucinta, rápida, a modo de pincelada, la actuación de los toreros constituirían las microestructuras de las crónicas. Éstas, desde el punto de vista periodístico, son las unidades informativamente más relevantes, pues contienen la descripción de las faenas de los toreros.

De esta forma, las crónicas de Ignacio Sánchez Mejías destacan por su plena coherencia discursiva, es decir, son una construcción donde cada parte ocupa su sitio, desempeña su función y se articula en referencia a todos y cada uno de los elementos que la conforman. El resultado que se presenta ante el lector es un texto unitario de difícil fragmentación, cuyo poder persuasivo engancha a los lectores 


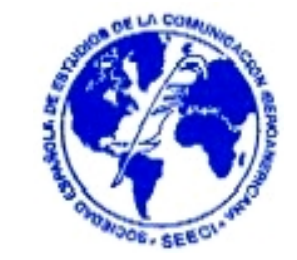

transmitiendo la sensación de que están presenciando los hechos que son explicados. Además, en esta parte central de la crónica es sobresaliente la sinceridad con que enjuicia su labor. Jamás se elogia sin sentido y la mayoría de las veces se convierte en el más severo de los jueces. Compruébese con el siguiente fragmento perteneciente a la crónica titulada "La casa de todos los toreros"

"Empieza la corrida. De los seis toros de Gamero Cívico, hay dos muy bravos, que me corresponden en suerte; el primero de ellos, achuchaba mucho por el lado izquierdo, llegó a ponerse verdaderamente peligroso. Lo dominé pronto y lo maté de un pinchazo y media estocada delantera. En el otro, que fue muy bueno, equivoqué el sitio de torear, malogrando una faena. Sólo dos pases naturales y dos de pecho guardaron relación con la bondad del toro, que a última hora no quería de la muleta. Lo maté de una estocada corta, delantera, atravesada y ligeramente desprendida" (Gil González, J.C., 2010, p. 29).

Esta muestra ejemplifica como ninguna otra la limpieza de su juicio, su rectitud en el ejercicio de la profesión periodística, su sinceridad y honradez para con los hechos enjuiciados y el tremendo respeto que le debe a los lectores. Ignacio Sánchez Mejías no busca ni recursos para tapar su actuación, ni posibles culpables que expliquen su falta de entendimiento con dos buenos toros. Ni la cuadrilla, ni el lote que le ha correspondido en suerte aparecen como causantes de su mala actuación. Él lo proclama sin aditamentos ni retruécanos retóricos transfiriendo a su audiencia la sensación de que lo narrado es la más seca de las verdades. Cualquiera podría haberse tapado aduciendo cualquier excusa. Esa triquiñuela, además de restarle credibilidad dañaría su imagen de hombre cabal.

Por otro lado, llama la atención que la mayoría de las crónicas cuente con una primera parte, a modo de introducción, cuya trama varía según las intenciones del 


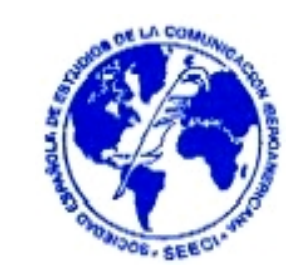

autor. Los temas tratados son de lo más variopinto. Algunos hacen referencia a los matices de la corrida ("La primera de Jerez"); otros aparecen como un pequeño relato histórico que sirve de pórtico a los comentarios de los avatares de la lidia y que sirven para matizar, encuadrar y entender el porqué del desarrollo de la lidia ("El toro embolado de Coimbra"); y en ocasiones, la crónica principia con una historia ficticia que nacía exclusivamente como consecuencia de su capacidad fabuladora ("Ése es el hijo del amo..."). Nos detenemos en este texto para destacar la volunta de Ignacio Sánchez Mejías de alejarse de la realidad que enjuicia.

En esta introducción utiliza la ficción como trasunto de una verdad cuyo sustento se encuentra en la realidad taurina. Con esta estrategia, el narrador se escuda en un artificio para poner en situación a lector, el cual, tendrá que esperar al desenlace final del texto para comprender esta licencia. La ficción aquí propuesta es una realidad que no siendo, adquiere vetas de verosimilitud por la certeza en la elección de la escena. El cronista lanza a sus lectores a un mundo de ensoñaciones, cuyo poder persuasivo está conseguido por el empleo adecuado de ciertos recursos (el costumbrismo de la escena, el ritmo de las descripciones, la elección del personaje, los diálogos, las expresiones populares) que hacen creíble y justificable esta fabulación.

Esta operación exige que Ignacio Sánchez Mejías sustente la trama en un lenguaje común, es decir, aquél que sirve al narrador para demostrar que la historia, aun siendo inventada, pudo pasar. A la par que describe una situación que embauca a los lectores transmite también sus destrezas lingüísticas y el conocimiento del uso de la jerga popular ("iArre Golondrino! ¡Arre Regalao! "iAprieta ese jorcate!" "iEndereza esa collera!'). La tarea creativa radica en la transformación del material procedente de la imaginación al mezclarlo con situaciones posibles en cualquier olivar del campo andaluz. Sin embargo, tras los fuegos de artificios nos encontramos con una prosa realista que acredita la existencia de una construcción en línea recta que avanza 


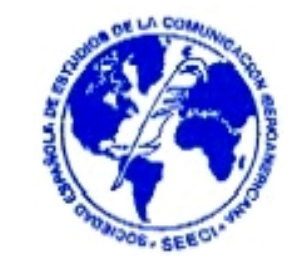

hacia un objetivo último: comenzar la narración del festejo, cuya lectura se convierte en condictio sine qua non para comprender la arquitectura de la crónica.

¿Cómo logró I gnacio Sánchez Mejías endosar verosimilitud a esta introducción? Con espontaneidad, es decir, ocultando los artificios con gran maestría, como si en el momento de la elaboración del texto el cronista prescindiese de la dispositio. La estrategia reside en construir un ambiente literario en el que el texto parece escribirse a la ligera, sin un plan preconcebido, en el que los hechos, las descripciones y los diálogos se van engarzando por casualidad. Una de las ventajas de esta simulada improvisación reside en provocar el nacimiento espontáneo de indicios de sinceridad que añaden una fuerza persuasiva fenomenal. En estas ocasiones demuestra su maestría formal y su inteligencia, porque, iniciando su crónica con un tema alejado del mundo de la actualidad taurina, consigue mediante recursos literarios impropios de un género periodístico (diálogos, descripciones, jerga, metáforas...) conducir al lector directamente a la narración de la corrida.

Estos juegos léxicos, esta ficción, esta suplantación del narrador por personajes que hablan desde su propia cosmovisión de la vida, cautivan a la audiencia. Gracias a esta estrategia va colando algunos argumentos extra-taurinos con tanto desparpajo y cadencia que parecieran formar parte del relato. Todos estos recursos literarios son exigencias estéticas que Ignacio Sánchez Mejías introduce para terminar de acicalar su relato y darle un sentido peculiar a sus postulados. Aparecen como un calco de su propia experiencia vital, de sus amistades, de sus gustos y apetitos taurinos y de sus relaciones con el mundo agrario, demostrando así que despliega su libertad de criterio sin obediencia a ningún imperativo lucrativo.

Ignacio Sánchez Mejías emplea su habilidad en el uso del lenguaje para introducir elementos interpretativos, juicios de opinión argumentados así como comparaciones y afirmaciones contundentes. Y lo más importante, consiguiendo un texto que no chirría a los ojos del lector que obtiene siempre una diferenciación nítida entre 


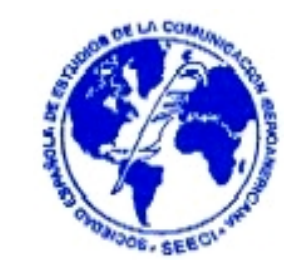

información y opinión. Estas crónicas taurinas se adhieren, por tanto, a la nueva corriente impresionista cuyo magisterio ejerce sin parangón alguno Gregorio Corrochano. Algunos críticos siguen haciendo revistas de toros, como por ejemplo Don Criterio en El Liberal. Éstas, tras la irrupción de la nueva técnica, no son nada más que una huella decimonónica en las que sobresalen sólo los datos estadísticos de la lidia de los seis toros y una breve reseña de la actuación de los matadores. Sin embargo, Ignacio Sánchez Mejías apuesta por la innovación que era el camino emprendido por Mariano de Cavia y José de la Loma D. Modesto.

El torero sevillano, por su fecunda imaginación, por su uso delicado y frondoso del lenguaje, por su facilidad para urdir arquitecturas de improbable comparación y por el despliegue inusitado de sentido común de su discurso, busca y encuentra la musicalidad en las crónicas taurinas. Este método, definido como impresionista y que como sostenía Ortega y Gasset "nada posee un perfil riguroso" (Cossío, J. M., 1987, p. 558), renuncia al relato minucioso de los hechos y ofrece un retazo, una pincelada suave, un rasgo leve de los momentos estelares del festejo. La crónica impresionista de Ignacio Sánchez Mejías describe la sensación de la faena antes que la puntillosa estadística de la misma.

Y como no podía ser de otra manera, el frontispicio de este ideal literario está sustentado en una base ética: el esclarecimiento de la verdad. Es decir los recursos estéticos no deben esconder el resplandor seráfico que produce la verdad cuando ésta es el resultado de un juicio riguroso y ceñido a los hechos: "la verdad sin adornos ni ropajes, ni apariencias que la disimulen, hace el efecto de un rayo de luz para los criticados".

Otro ejemplo de la corrupción que denunció I gnacio Sánchez Mejías y que ratifica su concepción ética de la vida está en la posdata de la crónica titulada "La casa de todos los toreros". En los últimos párrafos contesta a Fernando López Grosso, El chico del Baratillo, director de la revista taurina Seda y Oro sobre el asunto de la 


\section{REVISTA DE LA SEECI.}

Gil González, Juan carlos (2010): Ignacio Sánchez Mejías, un periodista de personalidad inquieta. No 21. Marzo. Año XIV. Páginas: 44-70

ISSN: 1576-3420 DOI: http://dx.doi.org/10.15198/seeci.2010.21.44-70

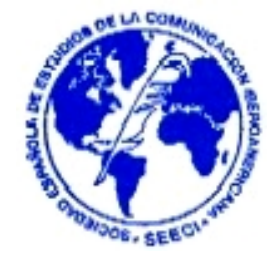

corrupción en el ejercicio de la crítica taurina, pues según Ignacio Sánchez Mejías, el semanario había demandado una subvención a la Asociación de Ganaderos para "fomentar" la Fiesta, y ésta se había negado. Este hecho le lleva a pensar que también habría obrado de igual forma con la Asociación de Empresarios, lo que explicaría la inquina que contra él se desprendía de los textos de El Liberal y de su propia revista. Así se mostró I gnacio Sánchez Mejías a lo largo de los cuatro meses en los que practicó la crónica taurina, sin renunciar a ninguna batalla.

\section{Los artículos de la polémica: Heraldo de Madrid}

Como muy bien sostuvo Adolfo Bio Casares hay patriotas negativos, a los que se les eriza la piel cuando alguien critica su país; y patriotas positivos, los que hacen algo útil por su patria. Ignacio Sánchez Mejías pertenecía a este segundo tipo y lo demostró cuando, ya abandonado el mundo del toro y volcado en las múltiples tareas creativas, decidió de nuevo lanzarse a la arena periodística para defender las corridas de toros de las invectivas que contra ellas lanzó J osé María Salaverría desde las páginas de $A b c$. No le gustó en absoluto al nuevo dramaturgo que el arte del toreo fuese identificado dentro de las cosas monstruosas de España.

Atacó directamente el tópico de relacionar la Tauromaquia con el flamenquismo, la gitanería y la España negra. Y no pasó por alto que fuese un germanófilo quien lo hiciese con la perversa confabulación del turismo alemán que comenzaba a descubrir nuestras tierras. Muy claro lo escribió Salaverría: “Mientras los españoles se obstinen en mantener las corridas de toros, será difícil extirpar de las imaginaciones extranjeras la idea de una España extravagante o monstruosa" (Salaverría, J. M., Abc 22 de mayo 1929).

Semejante afirmación, unida a las comparaciones precedentes, fueron consideradas una afrenta para Ignacio Sánchez Mejías y provocaron que su pluma aguda y hábil volviese a defender el toreo. En esta ocasión desde las páginas de El Heraldo de 


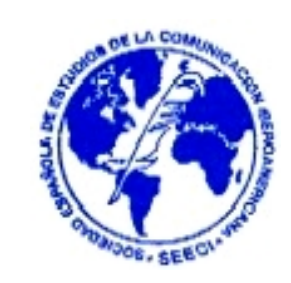

Madrid con seis artículos que van desde el 24 de mayo hasta el 6 de junio. Guardando siempre una educación exquisita hacia las opiniones contrarias, empleó Ignacio Sánchez Mejías en el primer artículo varias decenas de gramos de sarcasmo contra Salaverría. ¿Podrían abolirse las corridas de toros? Sí, reconoce el torero por su ineludible crueldad... pero, acábese, entonces, con todas las crueldades humanas, y primero por las provocadas por las guerras y dentro de ellas por los más modernos procedimientos: gases, aviación, submarinos...

Así lanzó, con ironía hiriente e intencionada, su dardo contra los alemanes. Parece mentira, viene a decirnos un Ignacio Sánchez Mejías metido a intelectual, que tengamos que suprimir las corridas de toros para favorecer el turismo de un pueblo como el alemán, que ha sido responsable directo del desencadenamiento de la Primera Guerra Mundial, con la cantidad de vidas inocentes que se perdieron y las fatigas que hubo de pasar la población europea para su reconstrucción. No pudo disimular su condición de encantador de serpientes, su carácter de seductor irrefrenable de las ideas con comparaciones metafóricas más efectistas que lógicas.

Esa puya hacia los alemanes no pasó desapercibida para la censura y provocó que su artículo quedase alterado, hasta tal punto que en el artículo publicado el 28 de mayo y titulado "Sobre la censura" Ignacio Sánchez Mejías se quejara amargamente: "Satisfecho con lo que creía obligación patriótica, mandé mis cuartillas al HERALDO, y al releer en él mi artículo, he quedado sorprendido de cómo la criba de la censura, al cernir mi propósito, debilitaba todos mis argumentos" (Sánchez Mejías, Heraldo de Madrid 28 de mayo de 1929). Nos interesa destacar que la polémica provocó que un intelectual cabal, de la talla de Miguel de Unamuno agitase su inteligencia contra el atropello que supone para los medios de comunicación no tener libertad de expresión. En su carta manuscrita que, nosotros reproducimos a pie de página, además, Unamuno se complace en compartir tareas intelectuales con Ignacio 


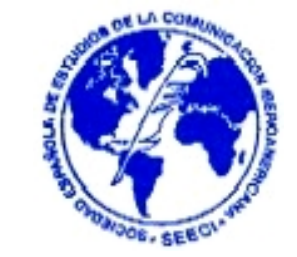

Sánchez Mejías: "estimándose su compañero de letras -y en ciertos respectos hasta de lidia, aunque no tauromáquica- se le ofrece amigo"2

"Las corridas de toros y los vendedores de plátanos" (30 de mayo) es un artículo en el que Ignacio Sánchez Mejías vuelve a criticar a las personas que atacan las corridas de toros porque según ellos perjudican el turismo. "Esa media docena de cursis" han olvidado que los hombres de talento universal que han visitado España han escrito maravillas del mundo de los toros, desde lord Bayron hasta Maurice Legendre, pasando por Merimée, Montherlant y Waldo Frank. Nos interesa destacar la filiación de Ignacio Sánchez Mejías con los intelectuales extranjeros del siglo XIX, a los que cita como si los manejase con toda naturalidad.

Además, para él Velázquez, Murillo, Goya y Santa Teresa se encuentran compartiendo grupo artístico con Joselito y Belmonte. Si los primeros, por sus obras, son reclamos para las mentes ilustradas extranjeras, no lo son menos los dos espadas sevillanos que fueron los protagonistas de la Edad de Oro del toreo. Para Ignacio Sánchez Mejías, a partir de Joselito y Belmonte, la corrida de toros es la manifestación clamorosa de la superioridad de la inteligencia sobre la fiereza, pues la función del torero es la de dominar a su adversario y su virtud reside en demostrarlo. Como cualquier otro artista, ser torero es exhibir su omnipotencia y, más en particular, mostrar el triunfo de la voluntad sobre el instinto.

\footnotetext{
2 Sr. D. Ignacio Sánchez Mejías:

No le conozco a usted, señor mío, ni como torero ni como escritor, pero tengo muy buenas referencias suyas. Sé que tiene muy buenos amigos, y lo sé por algunos suyos que lo son míos, y el que tiene buenos amigos es porque lo es bueno. $Y$ esto basa. Ahora lo que yo ignoraba es su importancia como escritor. $Y$ créame que como es español, me enorgullece el pensar que una opinión suya expuesta- lo he de creer- con toda serenidad, pueda molestar u ofender a las potencias extranjeras. A las potencias extranjeras jahí es nada! ¿No será que la censura - o el mentecato que la inspira- está ofendida o molestada porque la prensa extranjera no se aviene a someter a ella sus opiniones, si es que en ese pobre pueblo aherrojado y amordazado se celebra la reunión de la Sociedad de Naciones? De todos modos me satisface como español ver el valor intencional o mundial que la censura atribuye a sus opiniones. Las de Salaverría ni ofenden ni molestan a nadie.

Estimándose su compañero de letras -y en ciertos respectos hasta de lidia, aunque no tauromáquica-se le ofrece amigo.

Miguel de Unamuno

Hendaya (29-V-1929).
} 


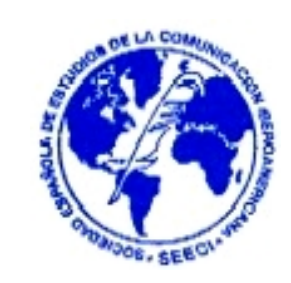

Su aliento irreverente, su humor demoledor se encuentra en los tres artículos siguientes titulados "Los nuevos sentimentales" (31 de mayo); "El guardia de la porra, director de lidia" (4 de junio); "Fakires contra teólogos" (6 de junio). En ellos hizo gala de su auctoritas de intelectual público comprometido con la Fiesta. Bochenski recoge el doble significado con el que se utiliza la expresión autoridad: "en unos casos designa una relación y en otros una propiedad" (Bochesnki, J. M., 1979, p. 21). El primero implica una relación con otros respecto a los cuales se goza de cierto prestigio o reconocimiento, con independencia del motivo; el segundo caso debe entenderse como una cualidad que acompaña a determinadas personas.

Ignacio Sánchez Mejías se introduce en estos tres artículos en una polémica tan antigua como las corridas de toros y que en cada época histórica reaparece con nuevos matices políticos. Los argumentos esgrimidos por los integrantes de la Sociedad Protectora de animales en el año 1929 son muy semejantes a los actuales. Cambian las personas pero no los argumentos. Sin embargo, nuestro protagonista es contundente. El toro de lidia es una fiera indómita que expresa en la plaza de toros todo su ímpetu combativo, todo su ardor guerrero y todo su potencial agresivo. No es un buey de carga, ni un lindo animalito de compañía. El toro de lidia, en tanto que un caso excepcional, ha sido seleccionado a lo largo de la historia y ha devenido en una especie única en el mundo gracias a la Fiesta de los toros.

El gran mérito de los toreros reside en esquivar los envites de la muerte con exquisita gracia. El torero se expone al pitón del toro y a la mirada inquisitiva de las personas y de la crítica, es decir, se ofrece por entero a la herida que traspasa su carne y a la vergüenza que lacera su alma. Por ello, sostenía I gnacio Sánchez Mejías que la ética del torero está muy emparentada con la ética estoica: es decir, "es una ética del ascesis (por oposición a las morales del bienestar); es una ética del ser (por oposición a las morales de la acción); es una ética del individuo excepcional, sabio o héroe (por oposición a las éticas comunes) y es una ética interna de la identificación 


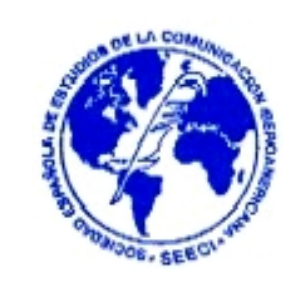

con el oficio propio - con el traje, si se quiere- (por oposición a las morales de la obediencia a mandatos exteriores)" (Wolff, F., 2008, p. 146). Por estas virtudes el torero, aunque se exponga a la cornada, no debe morir, y en caso de que se produjese la tragedia, nos encontraríamos ante un desgraciado accidente que como tal, no debería tomarse como la finalidad del arte del toreo.

Quizá el flanco más vulnerable y en el que la historia no le ha dado la razón fuese en su argumentario contrario al peto de los caballos de picar. Reconocía la repugnancia del destripamiento de los caballos en la plaza. Sin embargo, consideraba a los españoles como uno de los pueblos del mundo que más amaba a los equinos, por ello, consideraba la cogida del caballo como un mero error, una inaplicación de las estrictas normas de torear. Cita a Pepe-Hillo y su Tauromaquia, expone los argumentos de los picadores, ofrece las razones de D. Antonio y D. Eduardo Miura... para persuadir a lector que la muerte de los caballos es, a la circulación, como los accidentes de tráfico, una mera inobservancia de las normas. De su misma opinión era Gregorio Corrochano, que desde las páginas de $A B C$ también luchó de forma denodada para volver al origen. Sin embargo, el sentimentalismo actual no habría tolerado el espectáculo dantesco que supondría ver un jaco colgado de los pitones de un toro. En esta ocasión, Ignacio Sánchez Mejías no acertó en su comparación.

En todos estos artículos convergen las virtudes literarias de I gnacio Sánchez Mejías: la digresión novelesca; el trazo naturalista, el esbozo entre lo folletinesco y lo dramático, la fascinación por el toreo como manifestación artística y la trascendencia ética y moral de éste. Estos textos periodísticos muestran el talento creador del autor, es decir, la filosofía de su invención, y pueden entenderse como una declaración de principios estéticos de los que participa el torero sevillano. No sólo en las obras de teatro sino también en los escritos de la vieja tipografía impresa Ignacio Sánchez Mejías también ha volcado su alma, su enorme emoción y sensibilidad. Su producción de periódicos es un conjuro, un encantamiento, una necesidad por 


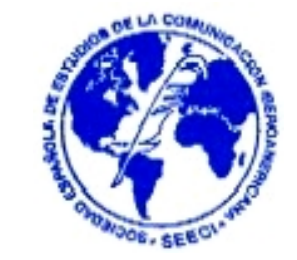

contarlo todo, desde los triunfos y las alegrías disfrutadas hasta el dolor y los quebrantos padecidos.

\section{Conclusión}

¿Fue realmente Sánchez Mejías periodista? Desde mi punto de vista, no, hecho que no empaña la dimensión polisémica de la figura de Sánchez Mejías. Un periodista es aquella persona que vive de contar e interpretar la realidad en los medios, es decir, vibra todos los días con el latir de los sucesos: los toros, la guerra, la política, las artes... y pone, de un lado, toda su inteligencia y, de otro, todo su buen hacer literario, para contárselo a su audiencia. Según este criterio, es demasiado generoso, considerar a Sánchez Mejías como periodista.

Su producción periodística es bastante breve y se desarrolla, en una primera etapa, en el periódico La Unión. En un segundo momento vuelve a echar mano del periodismo para, desde el Heraldo de Madrid contestar a José María Salaverría a un artículo sobre la "prohibición de las corridas de toros" que es censurado porque se considera que atenta contra los intereses del régimen de Primo de Rivera.

Sus textos publicados en el diario La Unión se pueden dividir en dos grupos. De un lado tendríamos, las cuatro primeras crónicas que se centran en un concurso de libres y galgos celebrado en Jerez con el patrocinio de 'La Ina'; publicadas los días $13,14,15$ y 16 de enero, y de otro, tendríamos los 18 textos, publicados con cierta periodicidad entre el 16 de abril y el 25 de julio.

Los textos publicados en enero son unas notas improvisadas por teléfono, sobre un acontecimiento del cual, el cronista es testigo directo y protagonista, como exige la profesión. Emplea un lenguaje sencillo, claro y directo en el que predominan las frases cortas y con el que intenta describir, con bastante tino, no sólo los hechos de las carreras de galgos, sino también todo lo concerniente a la organización. En estos 


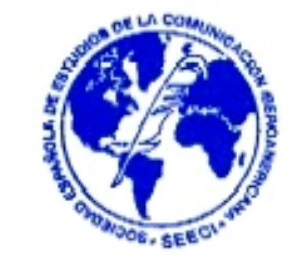

textos Sánchez Mejías se detiene en anécdotas sobre la velocidad, describe con un cierto deje costumbrista el campo andaluz, establece ciertos paralelismos entre la competición de las carreras y las competencias entre los toreros... y evidentemente, destacan algunas descripciones sobre los trajes cortos andaluces, indumentaria que conoce a la perfección.

Respecto de los 18 textos publicados con posterioridad, en puridad, no todos pueden considerarse crónicas taurinas, ni ensayos, ni cuentos como han dicho sus biógrafos. Podríamos decir, que 12 son crónicas taurinas (referencia a la polémica entre crítica y crónica). Y los seis textos restantes pertenecen a otros géneros. "El Homenaje a don Juan Valera" es un texto extraño porque se aparta de la materia taurina que vehicula a los 17 restantes, y podría catalogarse como un artículo de opinión, sobre un tema concreto.

"Recordatorio", "Los niños que juegan a ser hombres" e incluso "Los dos compadres" son columnas personales. "El gato que regalé a Belmonte" es un entretenidísimo reportaje de tema taurino sobre las supersticiones y "Contestando a una campaña" es una réplica a la polémica suscitada entre Galerín y Don Criterio.

¿Puede ser considerado Sánchez Mejías cronista taurino? Desde mi punto de vista sí, aunque su producción sea tan breve como intensa y esté marcada por la agria polémica con el periodista de la revista Seda y Oro, Agustín López Macías Galerín y el cronista taurino de El Liberal, Don Criterio.

Desde la Preceptiva de la Redacción Periodística, el la crónica es un género periodístico en el que se conjuga en perfecta simbiosis ciertas dosis de información con una interpretación razonada y cabal del desarrollo de cualquier acontecimiento que ofrezca a lector las claves necesarias para la comprensión profunda de un hecho. Para cumplir con tal cometido: 


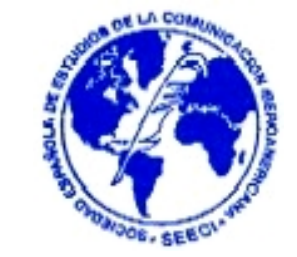

- El cronista debe estar en el lugar de los hechos, bien como testigo, bien como protagonista.

- Debe poseer unos conocimientos minuciosos del tema sobre el que va a desarrollar la crónica, es decir, debe ser un sabio en la materia.

- Su trabajo debe desarrollarse con cierta continuidad para que el contacto con los lectores establezca una suerte de lazo de unión entre ellos, y así el cronista, que debe hacer gala de una actitud didáctica sin pretenderlo, goce de credibilidad entre su audiencia.

Así pues, escribir una revista de toros, puede ser relativamente fácil, lo complicado es escribir una crónica taurina, y sobre todo, que ésta contenga un momento del toreo. No está al alcance de cualquiera encerrar en una frase ese amasijo de peligro y destreza, en el que intervienen el tiempo, el movimiento, la luz, las matemáticas y hasta un grito de mujer.

Esta labor ya no es tan sencilla, porque el toreo transmite una emoción íntima que no llega todo el mundo, porque no todos están capacitados espiritualmente para sentirla. Muchos, incluso, sólo se quedan en el colorido de la Fiesta, es decir, en el envoltorio exterior. Ignacio Sánchez Mejías demuestra que es de los que percibe lo interno, apenas se detiene en lo anecdótico y sabe centrarse en lo grave:

1.- Evidentemente Ignacio Sánchez Mejías es un maestro de su arte y conoce todas las interioridades del toreo, su técnica, su teoría, sus pases, los toros, los encastes, a los compañeros. Refiriéndose a una corrida de Juan Belmonte sostuvo "los toreros no suelen ser buenos aficionados a toros. Los toros muy bravos suelen ser difíciles para el diestro. Este toro, que es malo para el ganadero, es el ideal para nosotros. Es tan lógico todo esto que no es necesario razonarlo" (Gil González, J.C., 2010, p. 21).

2.- Además, asiste como testigo privilegiado a los hechos que enjuicia. No es sólo testigo, sino que además se convierte en protagonista. Ser protagonista y escribir de lo que se protagoniza le da al texto una dimensión extraordinaria, 


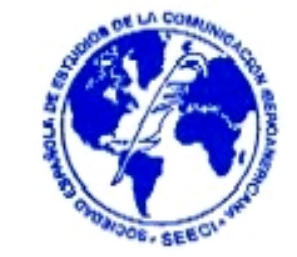

pues la crónica adquiere un plus de interés informativo, ya que permite a los lectores contar con las apreciaciones de alguien directamente implicado en los acontecimientos que se refieren.

3.- Desde el 16 de abril hasta el 25 de julio de 1925, Ignacio Sánchez Mejías acude con cierta periodicidad a su cita con los lectores. Su presencia en La Unión es corta pero intensa, y sobre todo, no renuncia a ninguna polémica, sobre todo, a la establecida con Galerín y Don Criterio. Lo interesante de esta polémica es que matador de toros sevillano desliza en sus respuestas, que estos periodistas cobran a tanto la línea, es decir, sugiere indirectamente que están cobrando de la Asociación de Empresarios, con los que el torero sevillano mantenía un agrio conflicto Vívidos ejemplos son las crónicas tituladas "El Criterio de Don Criterio" como contestación a la crónica que publicó El Liberal el 1 de mayo de 1925, en la que evaluaba la actuación de Sánchez Mejías en Jerez ante los Miuras.

4.- Para demostrar la cordialidad con sus lectores y su ánimo didáctico, en algunas crónicas, como es el caso de la titulada "Las enemistades de Aliatar" explica a su audiencia el famoso dicho, no hay quinto malo: "el quinto fue siempre para los ganaderos (antes de existir el sorteo) el lugar de honor para sus toros. Siempre se colocaba en ese turno el toro más bravo de la corrida. A tal extremo se llevó esta práctica, que todavía suele decirse no hay quinto malo" (Gil González, J.C., 2010, p. 20). Otra prueba de la soltura con la que se desenvuelve el cronista en su texto y que ejemplifica los lazos de unión simbólica que existen entre él como autor y su audiencia, se aprecia en la narración de las anécdotas. En la crónica titulada "Los niños que juegan a ser hombres" ofrece un breve apunte sobre la historia de los alguacilillos:

"Esos residuos que nos quedan del Tribunal del Santo Oficio, con sus trajes negros y sus caras demacradas y tristes, no le van bien a estas fiestas de chiquillos. No hacen falta. Su misión es evitar que se fuguen los que, faltos de ánimo y de ilusiones, no quieren estar en la plaza. Me explicaré. En cierta ocasión un extranjero muy 


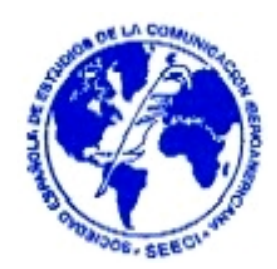

aficionado preguntaba a Fernando El Gallo por qué no se suprimían los alguaciles. ¡Quite usted, hombre! Si es lo que más falta hace! Si no fuera por ellos, cuando hacemos el paseo, al llegar a la presidencia, seguiríamos andando pa la calle. Fíjese cómo se paran delante de nosotros pa evitarlo" (Gil González, J.C., 2010, p. 61).

En definitiva, en las crónicas taurinas de Sánchez Mejías se advierte una decidida voluntad de estilo y la persecución de un ideal taurino. Además considera que el cronista taurino debe tender a lograr un ideal literario que esté cimentado en sólidas bases éticas. Y, como es bien sabido, el ejercicio de la crónica taurina ha sido con frecuencia una de las facetas menos transparentes de la profesión periodística. 


\section{Bibliografía}

$A B C$ (Sevilla), 22 de mayo de 1929.

AMORÓS, A (1999): Ignacio Sánchez Mejías. Alianza Editorial. Madrid.

BOCHESNKI, J.M. (1979): ¿Qué es autoridad? Introducción a la lógica de la autoridad. Herder. Barcelona.

Cossío, J. M. (1987): Los toros. Tratado técnico-histórico. Espasa-Calpe. Madrid.

FOUCAUTL, M. (1999): El Orden del discurso. Tusquets. Barcelona.

GIL GONZÁLEZ, J. C. (2010): Sobre tauromaquia. Obra periodística, entrevistas y conferencias. Berenice. Córdoba.

LAín ENTRALGO, P. (1999): “Prólogo" en Corrochano, G. Tauromaquia. Espasa. Madrid.

SÁNCHEZ MEJ ÍAS Mejías, I. "Sobre la censura" en El Heraldo de Madrid, 28 de mayo de 1929.

UNAMUNO, M.: "Carta a Ignacio Sánchez Mejías" en GIL GONZÁLEZ, J. C. (2010): Sobre tauromaquia. Obra periodística, entrevistas y conferencias, Berenice, Córdoba.

SALAVERRÍA, J. M. "El turno de los alemanes" en $A B C, 22$ de mayo de 1929.

VAN DIJ K, T. (1983): La ciencia del texto. Paidós Comunicación. Barcelona.

WOLFF, F. (2008): Filosofía de las corridas de toros. Bellaterra. Barcelona. 